\section{Time in Bed}

Helga Peter

Marburg, Deutschland

\section{Definition}

Messtechnischer Begriff in der Polysomnographie. Siehe $>$ „Polysomnographie und Hypnogramm“.

\title{
Synonyme
}

TIB 